\title{
Extracellular vesicles from oral squamous carcinoma cells display pro- and anti-angiogenic properties
}

\author{
de Andrade, A. L. D. L.
}

2018-07

de Andrade , A L D L , de Oliveira , C E , Dourado, M R, Macedo , C C S , Winck , F V , Paes Leme , A F , Salo , T , Coletta , R D , de Almeida Freitas , R \& Galvao , H C 2018 , ' Extracellular vesicles from oral squamous carcinoma cells display pro- and anti-angiogenic properties ' , Oral Diseases, vol. 24 , no. 5 , pp. 725-731 . https://doi.org/10.1111/odi.12765

http://hdl.handle.net/10138/303875

https://doi.org/10.1111/odi.12765

unspecified

publishedVersion

Downloaded from Helda, University of Helsinki institutional repository.

This is an electronic reprint of the original article.

This reprint may differ from the original in pagination and typographic detail.

Please cite the original version. 


\title{
Extracellular vesicles from oral squamous carcinoma cells display pro- and anti-angiogenic properties
}

\author{
ALDL de Andrade $^{1,2}$ (D) | CE de Oliveira ${ }^{2}$ | MR Dourado $^{2}$ | CCS Macedo ${ }^{2}$ | \\ FV Winck $^{3}$ | AF Paes Leme ${ }^{3}$ | T Salo ${ }^{2,4,5}$ | RD Coletta ${ }^{2}$ | R de Almeida Freitas ${ }^{1}$ | \\ HC Galvão ${ }^{1}$
}

\author{
${ }^{1}$ Department of Dentistry, Federal University \\ of Rio Grande do Norte, Natal, Brazil \\ ${ }^{2}$ Department of Oral Diagnosis, School of \\ Dentistry, University of Campinas, Piracicaba, \\ Brazil \\ ${ }^{3}$ Mass Spectrometry Laboratory, Biosciences \\ National Laboratory, LNBio, CNPEM, \\ Campinas, Brazil \\ ${ }^{4}$ Unit of Cancer Research and Translational \\ Medicine, Faculty of Medicine, Medical \\ Research Center Oulu, Oulu University \\ Hospital, University of Oulu, Oulu, Finland \\ ${ }^{5}$ Department of Pathology, Institute of Oral \\ and Maxillofacial Disease, HUSLAB, Helsinki \\ University Hospital, University of Helsinki, \\ Helsinki, Finland
}

\section{Correspondence}

Hébel Cavalcanti Galvão, Departamento de Odontologia, Universidade Federal do Rio Grande do Norte, Natal, Brazil.

Email: hebel.galvao@yahoo.com.br

Funding information

Fundação de Amparo à Pesquisa do Estado de São Paulo, Grant/Award Number: 2013/19856-2
Background: A new intercellular communication mode established by neoplastic cells and tumor microenvironment components is based on extracellular vesicles (EVs). However, the biological effects of the EVs released by tumor cells on angiogenesis are not completely understood. Here, we aimed to understand the biological effects of EVs isolated from two cell lines of oral squamous cell carcinoma (OSCC) (SCC15 and HSC3) on endothelial cell tubulogenesis.

Methods: OSCC-derived EVs were isolated with a polymer-based precipitation method, quantified using nanoparticle tracking analysis and verified for EV markers by dot blot. Functional assays were performed to assess the angiogenic potential of the OSCC-derived EVs.

Results: The results showed that EVs derived from both cell lines displayed typical spherical-shaped morphology and expressed the EV markers CD63 and Annexin II. Although the average particle concentration and size were quite similar, SCC15derived EVs promoted a pronounced tubular formation associated with significant migration and apoptosis rates of the endothelial cells, whereas EVs derived from HSC3 cells inhibited significantly endothelial cell tubulogenesis and proliferation.

Conclusion: The findings of this study reveal that EVs derived from different OSCC cell lines by a polymer-based precipitation method promote pro- or anti-angiogenic effects.

KEYWORDS

angiogenesis, extracellular vesicles, oral cancer

\section{1 | INTRODUCTION}

Tumor microenvironment consists of a specialized interface of noncancerous cells from diversified lineages, such as fibroblasts, immune and inflammatory cells, and endothelial cells, in addition to signaling factors and extracellular molecules, which may induce neoplastic progression (Azmi, Bao, \& Sarkar, 2013). All these elements favor tumor growth and invasion by promoting therapeutic resistance, defending the tumor from immune threats, and supplying nutrients, oxygen, and pathways of metastatic spread through vascular neoformation (Azmi et al., 2013; Bergers \& Benjamin, 2003; Folkman, 1995; Ziyad \& Iruela-Arispe, 2011). In fact, solid tumors progression can only occur in the simultaneous presence of angiogenesis.

Over the last years, essential pleiotropic roles associated with tumor development and progression have been attributed to extracellular vesicles (EVs) (Tauro et al., 2013). Due to the heterogeneity of the secreted vesicle sets, the nomenclature of their members is still conflicting and the term EV encompasses all of them (Gould \& 
Raposo, 2013). EVs are a group of secreted membrane-enclosed vesicles $(50-1,000 \mathrm{~nm})$ produced by all cell types, under pathological and physiological processes. These vesicles are loaded with proteins, lipids, microRNAs, RNAs, and DNAs and operate by releasing information to control the activity of recipient cells (D'Asti et al., 2012; Lemoinne et al., 2014; Lötvall et al., 2014; Minciacchi, Freeman, \& Di Vizio, 2015). EVs participate in tumor angiogenesis through the release of angiogenic proteins, such as transforming growth factor (TGF- $\beta$ ), fibroblast growth factor (FGF), platelet-derived growth factor (PDGF), and vascular endothelial growth factor (VEGF) or specific microRNAs, which may directly affect angiogenesis (Carmeliet, 2005; Zhang et al., 2015).

It has been recently shown that vesicles obtained from gastric cancer cells increase angiogenesis and tumor burden in mice (Stec et al., 2015). EVs derived from colorectal carcinoma cells carrying miR-1246 induce angiogenesis by the activation of SMAD cascade (Yamada et al., 2014), and EVs derived from renal carcinoma cells expressing CD105, a mesenchymal stem cell marker, not only collaborate with the activation of the angiogenic switch, but also guide tumor growth and metastatic spread (Grange et al., 2011). Sento, Sasabe, and Yamamoto (2016) have revealed that oral squamous cell carcinoma (OSCC) cells-derived EVs promoted neoplastic growth and expansion, nonetheless, the events triggered by these vesicles on endothelial cells are still incompletely understood.

Angiogenesis, as well as inductors and inhibitors of this process, can be evaluated in vitro through a series of assays involving proliferation, migration, apoptosis, and differentiation (Tahergorabi \& Khazaei, 2012). Expansion and migration of precursor cells prior to differentiation are essential for vessel formation. The formation of capillary-like tubes in vitro on basement membrane matrix, also known as tube formation assay, represents the later stage of the angiogenic process in which the endothelial cells differentiate into tubes simulating in vivo situation. In this study, we analyzed the biological roles of EVs derived from two OSCC lines, displaying low (SCC15) and high (HSC3) invasive behavior in the induction of angiogenesis in vitro.

\section{2 | MATERIALS AND METHODS}

\section{1 | Cell cultures}

Human umbilical vein endothelial cells (HUVEC) and the OSCC cell line SCC15 were purchased from American Type Culture Collection (ATCC, USA), whereas HSC3 was obtained from Japan Health Sciences Foundation (Osaka, Japan). SCC15 and HUVEC cells were cultured in a 1:1 mixture of Dulbecco's modified Eagle's media and Ham's F12 media (DMEM/F12; Invitrogen, USA) with $400 \mathrm{ng} / \mathrm{ml}$ hydrocortisone (Sigma-Aldrich, USA), 10\% fetal bovine serum (FBS), and antibiotics. HSC3 media contained DMEM/F12 with $400 \mathrm{ng} / \mathrm{ml}$ hydrocortisone, $10 \% \mathrm{FBS}$, antibiotics, and $50 \mu \mathrm{g} / \mathrm{ml}$ ascorbic acid. All cell lineages were maintained in a humidified incubator with $5 \% \mathrm{CO}_{2}$ at $37^{\circ} \mathrm{C}$.

\subsection{EV isolation}

OSCC cells $\left(8,500\right.$ cells $\left./ \mathrm{cm}^{2}\right)$ were plated and cultured in a media without serum for $24 \mathrm{hr}$. Conditioned media was harvested, and cleared by centrifugation, and EVs were purified with ExoQuick ${ }^{\mathrm{TM}}-\mathrm{TC}$ solution (SBI, Mountain View, California) in accordance with the instructions issued by the manufacturer. Purified EVs were conditioned at $-80^{\circ} \mathrm{C}$ in phosphate-buffered saline (PBS) for nanoparticle tracking analysis (NTA), dot blot assay, and transmission electron microscopy or were subjected to protein extraction in $30 \mu \mathrm{l}$ of urea buffer $(50 \mathrm{mM}$ Tris- $\mathrm{HCl} \mathrm{pH} \mathrm{7.5,} 8$ M urea, $2 \mathrm{M}$ thiourea, and $1 \mathrm{mM} \mathrm{DTT}$ ) (Winck et al., 2015).

\subsection{Nanoparticle tracking analysis (NTA)}

The characterization system (number and size) of OSCC-derived EVs was determined with the NanoSight NS300 instrument (NanoSight, Amesbury, United Kingdom). After 1:100 dilution with PBS, the samples were introduced into the 532-nm laser chamber with a constant and controlled flow at room temperature. Video capture and data analysis were performed with the software NTA 2.3 Build 0013. The concentration and size of individual particles were ascertained by their Brownian motion velocity. Particles with dimensions in the range of 100-1,000 nm were characterized as EVs (Winck et al., 2015).

\subsection{Dot blot assay}

The presence of the EV markers CD63 and Annexin II was verified by dot blot. A 96-well microfiltration unit was prepared using a nitrocellulose membrane (GE Healthcare, WI, USA) with a pore size of $0.45 \mu \mathrm{m}$. A suspension of $20 \mu \mathrm{l} /$ well of EVs $\left(3 \times 10^{10}\right.$ particles $)$ was added and vacuum dried. The membrane was then blocked by the addition of $10 \%$ non-fat dry milk in a $0.1 \%$ Tween-20 PBS solution for $2 \mathrm{hr}$ at room temperature. The incubation with the mouse anti-CD63 antibody (1:500, clone TS63; Invitrogen, USA) or mouse anti-annexin II antibody (1:1,000, clone 5/Annexin II aa. 123-328; BD Biosciences, USA) was followed by the incubation with secondary anti-mouse IgG fluorescein-conjugated antibody (1:1,000; Abcam, USA). Proteins were captured with an Alliance 9.7 instrument (UVITEC, Cambridge, UK).

\section{5 | Transmission electron microscopy}

EV preparations $\left(1 \times 10^{8}\right.$ vesicles) suspended in PBS were placed on copper grids covered by an ultrathin carbon film and positively charged (15 mA for $25 \mathrm{~s}$ ). A $2 \%$ solution of uranyl acetate dissolved in distilled water was used to perform a negative stain. The preparations were examined in a JEM-3010 transmission electron microscope with an operating power of $300 \mathrm{kV}$, and representative images were obtained (Winck et al., 2015)

\section{6 | Treatment}

After purification and quantification, EVs were stored at $-80^{\circ} \mathrm{C}$. To assess the effects of the EVs on endothelial cell phenotypes, cells were cultured in culture media containing $5 \times 10^{7}$ or $5 \times 10^{8} \mathrm{EVs} / \mathrm{ml}$. To comparison, cells were cultured in the same manner in the absence of EVs (negative control). 


\section{7 | Tube formation assay}

Cells were seeded in 96-well plates previously covered with $50 \mu \mathrm{l}$ of Matrige ${ }^{\circledR}$-GFR (BD Biosciences) in the presence or absence of OSCCproduced EVs for $12 \mathrm{hr}$ and at a density of 40,000 cells/well. An inverted microscope (Eclipse Ti-S; Nikon, Tokyo, Japan) was used to observe tube formation, and photomicrographs were acquired with the NIS Elements F 3.0 software (Nikon, Tokyo, Japan) and analyzed with the Motic Images Plus 2.0 software (Motic China Group Co.). The perimeter of the tubes was evaluated by delimiting and measuring the length of each tube.

\section{8 | Proliferation assay}

Cells were seeded in 96-well culture plates at a density of 10,000 cells/ well in $100 \mu \mathrm{l}$ of $10 \%$ FBS-supplemented media. Following $24 \mathrm{hr}$ of serum starvation, cells were incubated with or without OSCC-derived EVs for another $24 \mathrm{hr}$. Proliferation rates were determined by immunosorbent assay for the detection of Ki-67 (clone MIB-1, DAKO, Denmark) expression levels, as described previously (Klein, Wagner, Kirkpatrick, \& Van Kooten, 2000).

\section{9 | Migration assay}

Cell migration assay was conducted in $6.5-\mathrm{mm}$ transwell insert containing $8 \mu \mathrm{m}$ pores (Corning, USA). Serum-starved HUVEC cells $\left(8 \times 10^{4}\right.$ cells/well) were plated to the top chamber in $200 \mu \mathrm{l}$ of serum-free media with or without OSCC-produced EVs. The bottom chamber was completed with $500 \mu$ l of $10 \%$ FBS-supplemented media. Following $24 \mathrm{hr}$ of incubation, a cotton swab was used to carry out the gentle removal of non-migratory cells in the top compartment, and migratory cells that stayed on the lower surface of the membrane were subjected to fixation and staining with a $1 \%$ solution of toluidine blue/borax. Measuring absorbance was measured at $650 \mathrm{~nm}$.

\subsection{0 | Apoptosis analysis}

Cells were seeded in 6-well culture plates at a density of $2 \times 10^{5}$ cells/ well in $5 \mathrm{ml}$ of $10 \%$ FBS-supplemented media. Following $24 \mathrm{hr}$ of incubation with or without EVs derived from OSCC cells, the cellular apoptotic index was analyzed in a FACScalibur flow cytometer (BD Biosciences, USA) by quantifying annexin V-PE positive and 7-AAD negative cells as described previously (Bufalino et al., 2015).

\subsection{1 | Statistical analysis}

The results are reported as mean \pm standard derivation (SD). Statistical analysis was performed using Mann-Whitney's $U$ test or ANOVA, followed by Tukey's multiple comparisons test, and significance level was set at $5 \%(p \leq .05)$. All experiments were carried out, at least, in triplicates.

\section{3 | RESULTS}

\subsection{Characterization of the OSCC-derived EVs}

Morphological characterization revealed that OSCC-derived EVs exhibited an integral and rounded surface without any apparent intervesicular fusion or aggregation (Figure 1a). As shown in Figure 1b, both OSCC-derived EVs were enriched with CD63 and Annexin II, but a higher expression was detected in EVs derived from HSC3 cells. Moreover, the average particle concentration and size distribution of the EVs from SCC15 $\left(3.37 \pm 0.45 \times 10^{10}\right.$ and $142.06 \pm 24.24 \mathrm{~nm}$, respectively; Figure 1c) and HSC3 $\left(2.79 \pm 0.55 \times 10^{10}\right.$ and $166.06 \pm 7.60 \mathrm{~nm}$, respectively; Figure $1 \mathrm{~d}$ ) did not show significant variation.

\section{2 | SCC15-derived EVs induce angiogenesis}

To evaluate the effects of SCC15-derived EVs in the processes related to angiogenesis, HUVEC cells were cultured with increasing EV concentrations and assessed in proliferation, migration, apoptosis, and tube formation assays. Even at highest concentration, SCC15-derived EVs did not alter significantly the proliferation of HUVEC cells (Figure 2a). At $5 \times 10^{7} \mathrm{EVs}$, proliferation was reduced in $\sim 32 \%$ (mean $31.7 \% \pm 16.7$ ) $(p=.36$ ), and the treatment with $5 \times 10^{8} \mathrm{EVs}$ showed great variability, with a mean of induction of $\sim 12 \%$ (mean $12.9 \% \pm 64.2$ ) ( $p=.95$ ). However, the treatment with $5 \times 10^{8}(p=.03)$ SCC15-derived EVs promoted a significant increase in the number of apoptotic cells in comparison with the control (Figure 2b). Additionally, increased cell motility was detected after treatment with $5 \times 10^{7}$ and $5 \times 10^{8}$ particles $(p=.02$ and $p=.03$, respectively, Figure 2c). Significant tube formation was identified when HUVEC cells were incubated with SCC15-derived EVs (Figure 2d,e). In fact, a significantly higher number of tubes were observed as the concentrations of EVs increased ( $p=.02$ for $5 \times 10^{7} \mathrm{EVs}$ and $p=.0001$ for $5 \times 10^{8} \mathrm{EVs}$ ). However, no expressive alterations were identified in the length of vascular tubes (Figure 2f).

\section{3 | HSC3-derived EVs suppress angiogenesis}

The effects of the EVs released by the highly invasive HSC3 cells were also analyzed in HUVEC cells. HUVEC cells incubated with $5 \times 10^{7}$ and $5 \times 10^{8} \mathrm{EVs}$ reduced the Ki67-labeling index by approximately $35 \%$ (mean $35.1 \% \pm 25.8$ ) and $40 \%$ (mean $40.1 \% \pm 12.9$ ), respectively, in comparison with the control without EVs. However, a significant reduction in the proliferation of HUVEC cells was observed only after treatment with $5 \times 10^{8} \mathrm{EVs}(p=.05)$ (Figure 3a). No significant effects on apoptosis or migration rate were associated with HSC3-derived EVs (Figure 3b,c). On the other hand, a progressive suppression of tubulogenesis, characterized by a significantly lower number of tubes, was observed at concentration of $5 \times 10^{8} \mathrm{EVs}(p=.04$, Figure $3 \mathrm{~d}, \mathrm{e})$. No significant differences in the total tube length were observed (Figure 3f). 


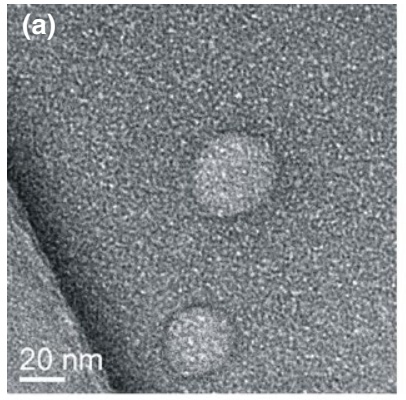

(b)

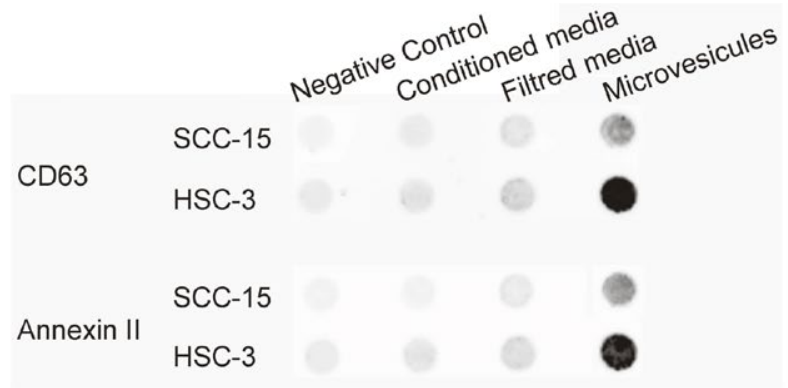

(d)

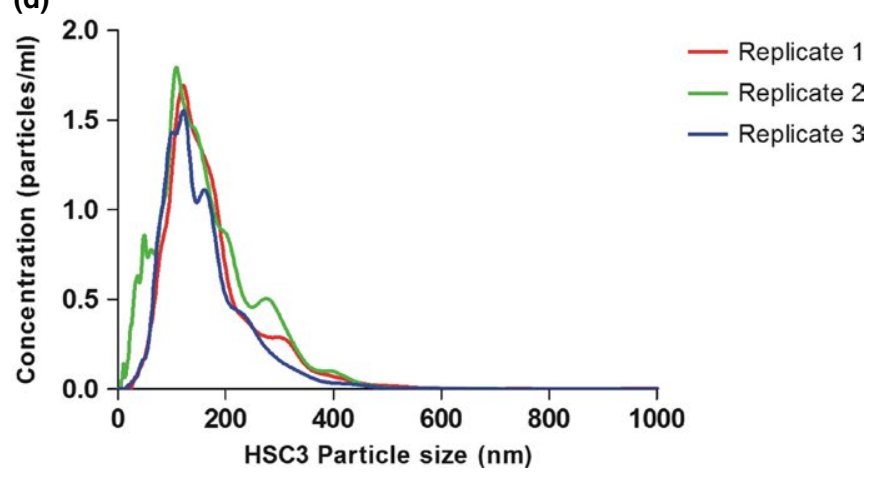

(c)

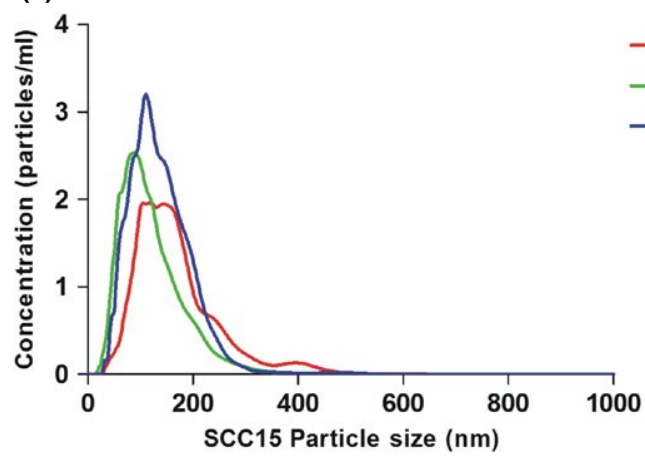

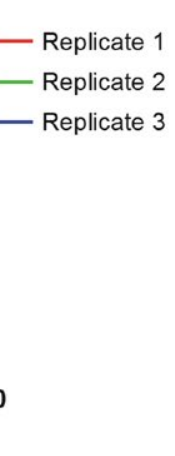

FIGURE 1 Morphological characterization of OSCC-derived EVs. (a) Transmission electron microcopy of OSCC-derived EVs revealed structures with an integral and rounded surface (Scale bar = $20 \mathrm{~nm}$ ). (b) Detection of CD63 and Annexin II expressions in OSCC-derived EVs by dot blot. Average concentration and size distribution of EVs isolated from SCC15 (c) and HSC3 (d) cells in three independent experiments by nanoparticle tracking analysis [Colour figure can be viewed at wileyonlinelibrary.com]
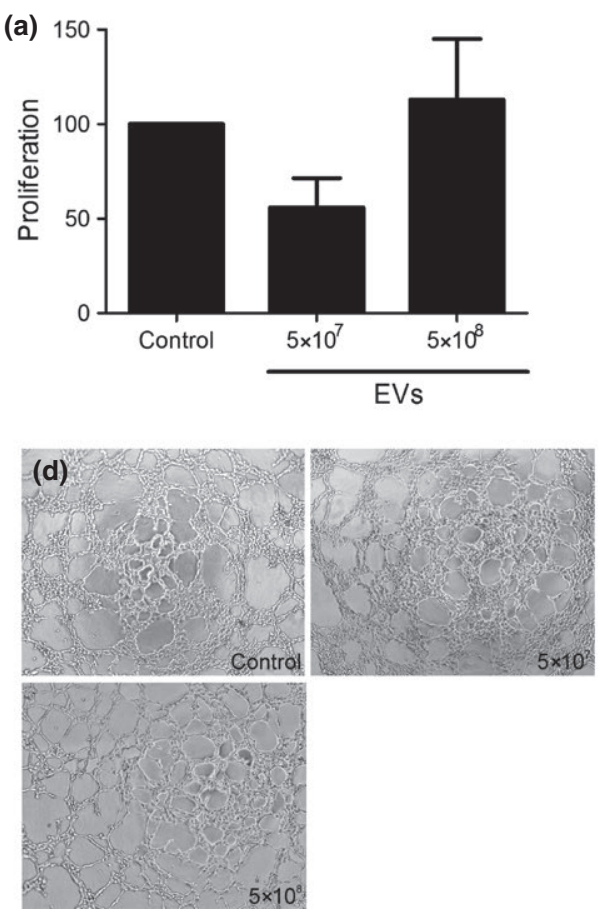

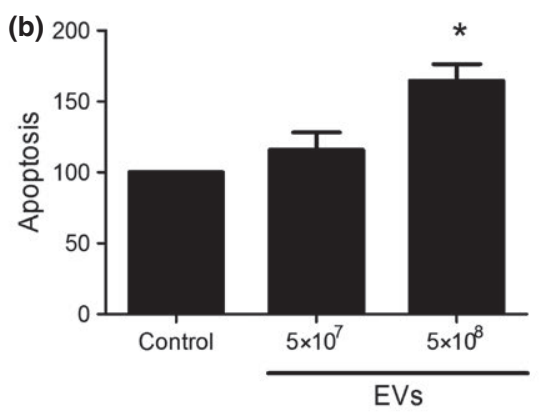

(e)

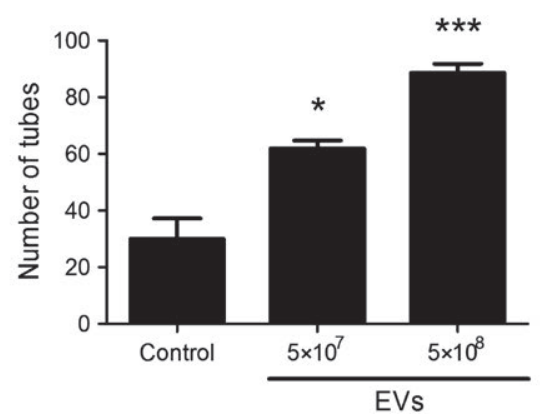

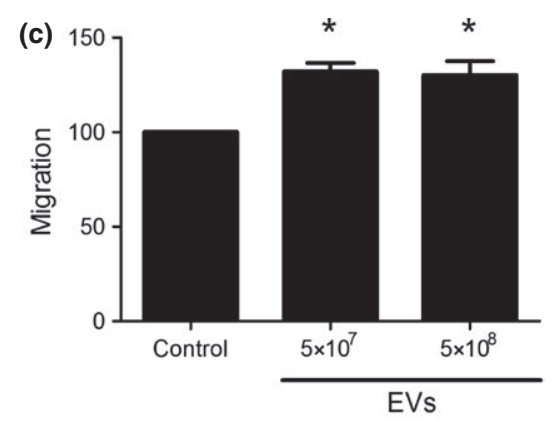

(f)

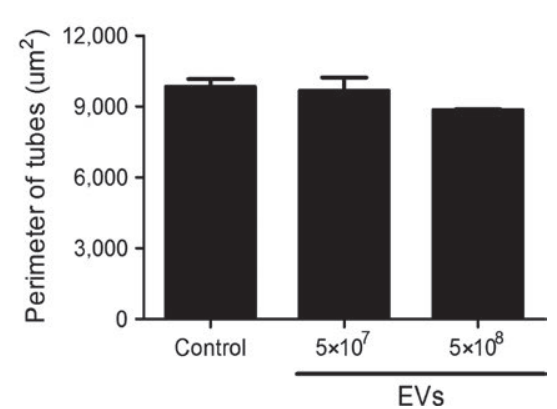

FIGURE 2 SCC15-derived EVs promote angiogenesis. (a) The proliferation assay based on detection of the Ki-67 protein did not show a significant induction of HUVEC cell proliferation. (b) Apoptosis of HUVEC cells was significantly induced after the treatment with $5 \times 10^{8}$ ( $p=.03$ ) SCC15-derived EVs. (c) Migration of HUVEC cells was significantly induced at the concentrations of $5 \times 10^{7}$ and $5 \times 10^{8}$ particles ( $p=.02$ and $p=.03$, respectively). (d) Representative photomicrographs showing a significant tube formation after the treatment with SCC15derived EVs for $24 \mathrm{hr}$ (original magnifications of $40 \times$ ). (e) All concentrations of SCC15-derived EVs produced a higher number of vascular tubes ( $p=.02$ for $5 \times 10^{7}$ particles and $p=.0001$ for $5 \times 10^{8}$ particles). (f) No significant alterations were observed on the length of vascular tubes. Bars represent the means $\pm S D$ of three independent experiments. ${ }^{*} p \leq .05$ and ${ }^{* * *} p \leq .001$ 

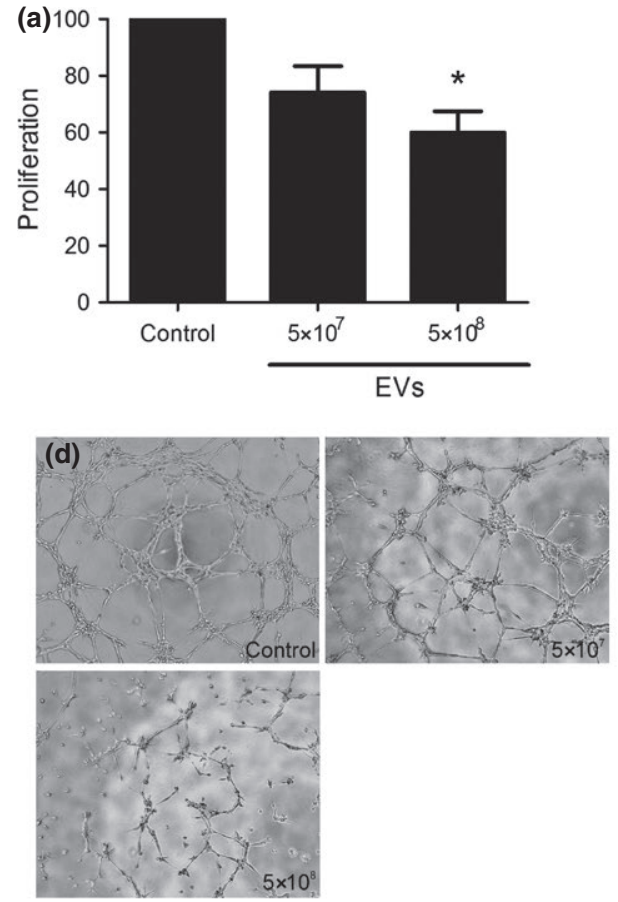

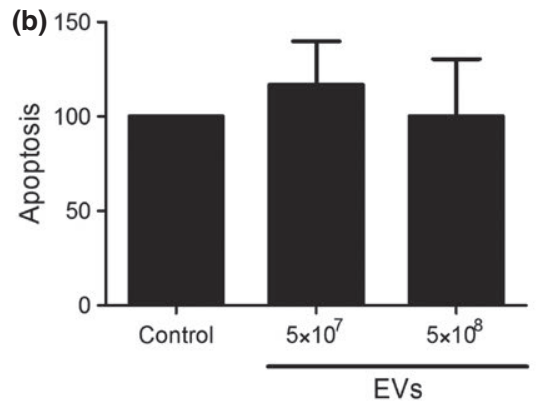

(e)

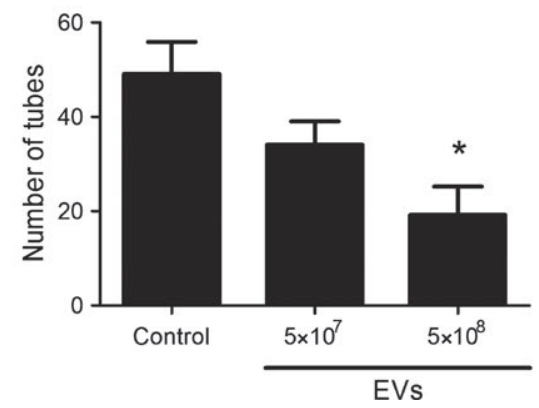

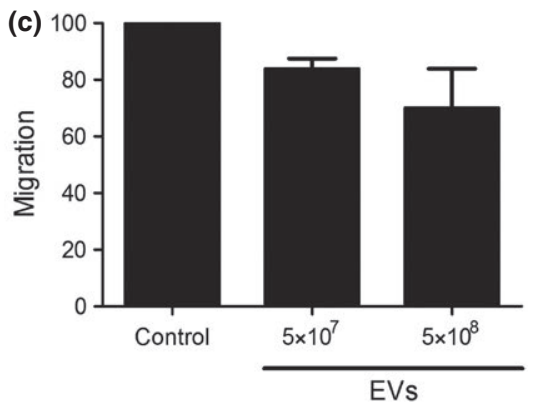

(f)

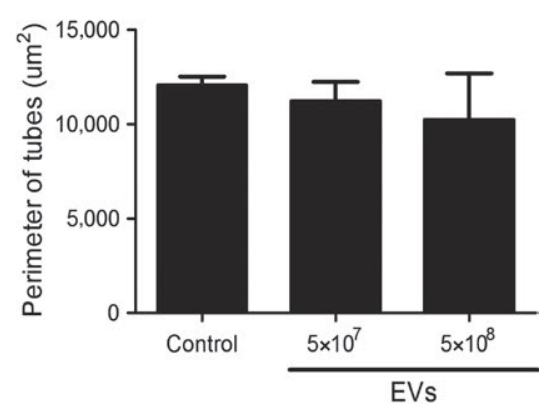

FIGURE 3 HSC3-derived EVs block endothelial-like tube formation. (a) The proliferation of HUVEC cells was significantly inhibited at the concentration of $5 \times 10^{8}$ HSC3-derived EVs $(p=.05)$. No significant effects on apoptosis (b) or migration (c) were associated with HSC3derived EVs. (d) Representative photomicrographs showing a significant reduction in tube formation after the treatment with HSC3-derived EVs for $24 \mathrm{hr}$ (original magnifications of 40x). (e) All concentrations of HSC3-derived EVs produced a progressive suppression in tubulogenesis, and a significant lower number of vascular tubes were observed at the concentration of $5 \times 10^{8}$ HSC3-derived EVs ( $\left.p=.04\right)$. (f) No significant alterations were observed on the length of vascular tubes. Bars represent the means $\pm S D$ of three independent experiments. ${ }^{*} p \leq .05$

\section{DISCUSSION}

The dynamic and reciprocal interactions established between cancer cells and the tumor microenvironment orchestrate critical aspects for the development of primary and metastatic tumors, as well as for maintaining a permissive environment at the tumor-stromal interface. One way by which cancer cells can establish communication and modifications in the surrounding tissues is through the release of EVs (Atay \& Godwin, 2014). Within this context, the present study aimed to characterize OSCC-derived EVs and to evaluate their effects on angiogenesis in vitro.

Under electron microscopy, EVs derived from both cell lines exhibited the classical spherical aspect and expressed the transmembrane protein CD63 and the cytosolic protein Annexin II, which are supposed to be enriched in EVs (Lötvall et al., 2014). However, despite secreting similar amounts and size distribution of vesicles, HSC3derived EVs presented higher amounts of those markers compared with SCC15-derived EVs, a fact that can reflect differences in the content, source, or release process of the two cell lines (Willms et al., 2016). Increased production of EVs by tumor cells occurs to facilitate the intercellular communication and to support the tumor growth in different ways (Zlotogorski-Hurvitz, Dayan, Chaushu, Salo, \& Vered, 2016). In accordance with this and comparing to the previous studies using the same method of quantification, we obtained higher EV yields by the polymer-based precipitation method compared with sequential gel filtration (Heinemann et al., 2014) and ultracentrifugation
(Zlotogorski-Hurvitz et al., 2016). In addition to the fact that different tumor cells are able to produce higher amounts of EVs in comparison with non-neoplastic cells (Taylor \& Gercel-Taylor, 2008), these data also reflect the efficiency of the methodology used in this study. Moreover, the diagnostic applicability of EV recovery with same method was confirmed in earlier publications (Shin et al., 2015; Yap et al., 2017). This methodology also enabled us to obtain EVs of similar size from both OSCC cells, in contrast to wide range of nanoparticle size distribution previously reported (Zlotogorski-Hurvitz et al., 2016). However, despite their seemingly homogenous characteristics, our results showed that EVs derived from different OSCC lines mediated distinct effects on the angiogenic properties of recipient endothelial cells.

SCC15-derived EVs induced significantly HUVEC migration and tube formation, and EVs derived from HSC3 inhibited significantly the proliferation and tube formation. Like non-neoplastic tissues, cancers need stromal support and $\mathrm{O}_{2}$, as well as an alternative pathway to eliminate $\mathrm{CO}_{2}$ and metabolic residual products (Hanahan \& Weinberg, 2011). Therefore, the pro-angiogenic phenotype induced by SCC15-derived EVs can be explained by the fact that the angiogenic process is fundamental for tumor progression and metastatic spread. Previous studies have shown that EV uptake can induce upregulation of angiogenesis-related genes, promoting endothelial cell proliferation, migration, and sprouting (Nazarenko et al., 2010). Regarding the apoptotic effects triggered by SCC15-derived EVs on HUVEC cells, our results showed an increased number of apoptotic cells. In addition to its involvement in the remodeling, homeostasis, 
and development of blood vessels, this elevated apoptotic index can equally contribute to the angiogenic process and to during the phase of tubular morphogenesis (Affara et al., 2007).

In contrast, the anti-angiogenic properties of EVs produced by HSC 3 cells highlight the complexity and heterogeneity in which these structures perform their function in the tumor microenvironment (Meehan \& Vella, 2016). Anti-angiogenic effects of EVs generated in vitro from various cell types or isolated from plasma have been associated with the activation of the CD36-dependent signaling pathway, which inhibits microvascular cell migration and tube formation. Furthermore, HSC3 cells are highly aggressive and hypoxia-responsive (Teppo et al., 2013), and exogenous hypoxia is an important factor with a strong impact on EV secretion, load, and consequently, on angiogenic properties (Webber, Yeung, \& Clayton, 2015). More potent angiogenesis has been associated with EVs obtained from glioblastoma and multiple myeloma cells during hypoxic exposures (Kucharzewska et al., 2013; Umezu et al., 2014). Moreover, leukemia cells under hypoxia are significantly enriched with miR-210 that promotes the EV angiogenic activity (Tadokoro, Umezu, Ohyashiki, Hirano, \& Ohyashiki, 2013). Thus, further studies should be conducted to assess the content and the effects produced by HSC3-derived EVs obtained under hypoxic conditions.

\section{5 | CONCLUSIONS}

In closing, our findings reflect the complexity of the coordinated events and interactions related to tumor angiogenesis mediated by EVs. While SCC15 cell-derived EVs promoted a pronounced angiogenic response as well as high apoptosis and cellular migration of endothelial cells, EVs secreted by the more invasive HSC3 cell line showed opposite effects. These results not only increase our understanding of the interactions between tumor-derived EVs and endothelial cells but may also contribute to future investigations on EVs and to the evolution of therapies that use EVs as target.

\section{ACKNOWLEDGEMENTS}

The authors would like to thank the Procad/Casadinho-CNPq/CAPES, Brasília, Brazil, and the Fundação de Amparo a Pesquisa do Estado de São Paulo-FAPESP, São Paulo, Brazil (2013/19856-2), for their financial support of this research.

\section{AUTHOR CONTRIBUTION}

Ana Luiza Dias Leite de Andrade, Carine Ervolino de Oliveira, Maurício da Rocha Dourado, and Carolina Carneiro Soares Macedo contributed with laboratory assays, analysed the data, and drafted the manuscript. Flávia Vischi Winck was responsible for characterization tests. Adriana Franco Paes Leme designed the study and contributed with characterization tests. Tuula Salo designed the study. Ricardo D. Coletta designed the study, analysed the data, and drafted the manuscript. Roseana de Almeida Freitas and Hébel Cavalcanti Galvão designed the study and drafted the manuscript.

\section{ORCID}

ALDL Andrade (iD http://orcid.org/0000-0002-0068-9050

\section{REFERENCES}

Affara, M., Dunmore, B., Savoie, C., Imoto, S., Tamada, Y., Araki, H., ... Print, C. (2007). Understanding endothelial cell apoptosis: What can the transcriptome, glycome and proteome reveal? Philosophical Transactions of the Royal Society of London. Series B, Biological Sciences, 362, 1469-1487.

Atay, S., \& Godwin, A. K. (2014). Tumor-derived exosomes: A message delivery system for tumor progression. Communicative \& Integrative Biology, 7, e28231.

Azmi, A. S., Bao, B., \& Sarkar, F. H. (2013). Exosomes in cancer development, metastasis, and drug resistance: A comprehensive review. Cancer and Metastasis Reviews, 32, 623-642.

Bergers, G., \& Benjamin, L. E. (2003). Tumorigenesis and the angiogenic switch. Nature Reviews Cancer, 3, 401-410.

Bufalino, A., Cervigne, N. K., de Oliveira, C. E., Fonseca, F. P., Rodrigues, P. C., Macedo, C. C., ... Coletta, R. D. (2015). Low miR-143/miR-145 cluster levels induce activin A overexpression in oral squamous cell carcinomas, which contributes to poor prognosis. PLoS ONE, 10, e0136599.

Carmeliet, P. (2005). Angiogenesis in life, disease and medicine. Nature, 438, 932-936.

D’Asti, E., Garnier, D., Lee, T. H., Montermini, L., Meehan, B., \& Rak, J. (2012). Oncogenic extracellular vesicles in brain tumor progression. Frontiers in Physiology, 3, 294.

Folkman, J. (1995). Angiogenesis in cancer, vascular, rheumatoid and other disease. Nature Medicine, 1, 27-31.

Gould, S. J., \& Raposo, G. (2013). As we wait: Coping with an imperfect nomenclature for extracellular vesicles. The Journal of Extracellular Vesicles, 2, 20389.

Grange, C., Tapparo, M., Collino, F., Vitillo, L., Damasco, C., Deregibus, M. C., ... Camussi, G. (2011). Microvesicles released from human renal cancer stem cells stimulate angiogenesis and formation of lung premetastatic niche. Cancer Research, 71, 5346-5356.

Hanahan, D., \& Weinberg, R. A. (2011). Hallmarks of cancer: The next generation. Cell, 144, 646-674.

Heinemann, M. L., Ilmer, M., Silva, L. P., Hawke, D. H., Recio, A., Vorontsova, M. A., ... Vykoukal, J. (2014). Benchtop isolation and characterization of functional exosomes by sequential filtration. Journal of Chromatography A, 1371, 125-135.

Klein, C. L., Wagner, M., Kirkpatrick, C. J., \& Van Kooten, T. G. (2000). A new quantitative test method for cell proliferation based on detection of the Ki-67 protein. Journal of Materials Science. Materials in Medicine, 11, 125-132.

Kucharzewska, P., Christianson, H. C., Welch, J. E., Svensson, K. J., Fredlund, E., Ringnér, M., ... Belting, M. (2013). Exosomes reflect the hypoxic status of glioma cells and mediate hypoxia-dependent activation of vascular cells during tumor development. Proceedings of the National Academy of Sciences of the United States of America, 110, 7312-7317.

Lemoinne, S., Thabut, D., Housset, C., Moreau, R., Valla, D., Boulanger, C. M., \& Rautou, P. E. (2014). The emerging roles of microvesicles in liver diseases. Nature Reviews Gastroenterology \& Hepatology, 11, 350-361.

Lötvall, J., Hill, A. F., Hochberg, F., Buzás, E. I., Di Vizio, D., Gardiner, C., ... Théry, C. (2014). Minimal experimental requirements for definition of extracellular vesicles and their functions: A position statement from the International Society for Extracellular Vesicles. The Journal of Extracellular Vesicles, 3, 26913. 
Meehan, K., \& Vella, L. J. (2016). The contribution of tumour-derived exosomes to the hallmarks of cancer. Critical Reviews in Clinical Laboratory Sciences, 53, 121-131.

Minciacchi, V. R., Freeman, M. R., \& Di Vizio, D. (2015). Extracellular vesicles in cancer: Exosomes, microvesicles and the emerging role of large oncosomes. Seminars in Cell \& Developmental Biology, 40, 41-51.

Nazarenko, I., Rana, S., Baumann, A., McAlear, J., Hellwig, A., Trendelenburg, M., ... Zöller, M. (2010). Cell surface tetraspanin Tspan8 contributes to molecular pathways of exosome-induced endothelial cell activation. Cancer Research, 70, 1668-1678.

Sento, S., Sasabe, E., \& Yamamoto, T. (2016). Application of a persistent heparin treatment inhibits the malignant potential of oral squamous carcinoma cells induced by tumor cell-derived exosomes. PLOS ONE, 11, e0148454.

Shin, H., Han, C., Labuz, J. M., Kim, J., Kim, J., Cho, S., ... Park, J. (2015). Park, High-yield isolation of extracellular vesicles using aqueous two-phase system. Scientific Reports, 5, 13103.

Stec, M., Szatanek, R., Baj-Krzyworzeka, M., Baran, J., Zembala, M., Barbasz, J., ... Zembala, M. (2015). Interactions of tumour-derived micro(nano) vesicles with human gastric cancer cells. Journal of Translational Medicine, 13, 376.

Tadokoro, H., Umezu, T., Ohyashiki, K., Hirano, T., \& Ohyashiki, J. H. (2013). Exosomes derived from hypoxic leukemia cells enhance tube formation in endothelial cells. Journal of Biological Chemistry, 288, 34343-34351.

Tahergorabi, Z., \& Khazaei, M. (2012). A review on angiogenesis and its assays. Iranian Journal of Basic Medical Sciences, 15, 1110-1126.

Tauro, B. J., Greening, D. W., Mathias, R. A., Mathivanan, S., Ji, H., \& Simpson, R. J. (2013). Two distinct populations of exosomes are released from LIM1863 colon carcinoma cell-derived organoids. Molecular \& Cellular Proteomics: MCP, 12, 587-598.

Taylor, D. D., \& Gercel-Taylor, C. (2008). MicroRNA signatures of tumorderived exosomes as diagnostic biomarkers of ovarian cancer. Gynecologic Oncology, 110, 13-21.

Teppo, S., Sundquist, E., Vered, M., Teppo, S., Sundquist, E., Vered, M., ... Nyberg, P. (2013). The hypoxic tumor microenvironment regulates invasion of aggressive oral carcinoma cells. Experimental Cell Research, 319, 376-389.
Umezu, T., Tadokoro, V., Azuma, K., Yoshizawa, S., Ohyashiki, K., \& Ohyashiki, J. H. (2014). Exosomal miR-135b shed from hypoxic multiple myeloma cells enhances angiogenesis by targeting factor-inhibiting HIF-1. Blood, 124, 3748-3757.

Webber, J., Yeung, V., \& Clayton, A. (2015). Extracellular vesicles as modulators of the cancer microenvironment. Seminars in Cell \& Developmental Biology, 40, 27-34.

Willms, E., Johansson, H. J., Mäger, I., Lee, Y., Blomberg, K. E., Sadik, M., ... Vader, P. (2016). Cells release subpopulations of exosomes with distinct molecular and biological properties. Scientific Reports, 6, 22519.

Winck, F. V., Prado Ribeiro, A. C., Ramos Domingues, R., Ling, L. Y., RiañoPachón, D. M., Rivera, C., ... Paes Leme, A. F. (2015). Insights into immune responses in oral cancer through proteomic analysis of saliva and salivary extracellular vesicles. Scientific Reports, 5, 16305.

Yamada, N., Tsujimura, N., Kumazaki, M., Shinohara, H., Taniguchi, K., Nakagawa, Y., ... Akao, Y. (2014). Colorectal cancer cell-derived microvesicles containing microRNA-1246 promote angiogenesis by activating Smad 1/5/8 signaling elicited by PML down-regulation in endothelial cells. Biochimica et Biophysica Acta, 1839, 1256-1272.

Yap, T., Vella, L. J., Seers, C., Nastri, A., Reynolds, E., Cirillo, N., \& McCullough, M. (2017). Oral swirl samples - robust source of microRNA protected by extracellular vesicles. Oral Diseases, 23, 312-317.

Zhang, X., Yuan, X., Shi, H., Wu, L., Qian, H., \& Xu, W. (2015). Exosomes in cancer: Small particle, big player. Journal of Hematology \& Oncology, 8, 83.

Ziyad, S., \& Iruela-Arispe, M. L. (2011). Molecular mechanisms of tumor angiogenesis. Genes Cancer, 2, 1085-1096.

Zlotogorski-Hurvitz, A., Dayan, D., Chaushu, G., Salo, T., \& Vered, M. (2016). Morphological and molecular features of oral fluid-derived exosomes: Oral cancer patients versus healthy individuals. Journal of Cancer Research and Clinical Oncology, 142, 101-110.

How to cite this article: de Andrade ALDL, de Oliveira CE, Dourado MR, et al. Extracellular vesicles from oral squamous carcinoma cells display pro- and anti-angiogenic properties. Oral Dis. 2018;24:725-731. https://doi.org/10.1111/odi.12765 